\title{
Current perspectives on pharmacist home visits: do we keep reinventing the wheel?
}

This article was published in the following Dove Press journal: Integrated Pharmacy Research and Practice

\section{Priti S Flanagan ${ }^{1,2}$ \\ Andrea Barns'}

'Pharmacy Community Programs, Lower Mainland Pharmacy Services, Langley, BC, Canada; ${ }^{2}$ Faculty of Pharmaceutical Sciences, University of British Columbia, Vancouver, BC, Canada

Video abstract

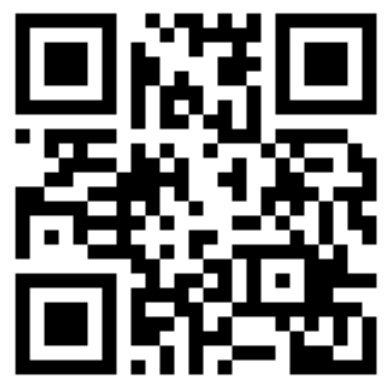

Point your SmartPhone at the code above. If you have a QR code reader the video abstract will appear. Or use: http://youtu.be/IGqakjewsce
Correspondence: Priti S Flanagan Lower Mainland Pharmacy Services, 2nd Floor, 852I 198A Street, Langley, BC V2Y ØAI, Canada

$\mathrm{Tel}+$ I 604455 I 328 (ext 74|403)

Email priti.flanagan@fraserhealth.ca

\begin{abstract}
The scope of clinical pharmacy services available in outpatient settings, including home care, continues to expand. This review sought to identify the evidence to support pharmacist provision of clinical pharmacy services in a home care setting. Seventy-five reports were identified in the literature that provided evaluation and description of clinical pharmacy home visit services available around the world. Based on results from randomized controlled trials, pharmacist home visit interventions can improve patient medication adherence and knowledge, but have little impact on health care resource utilization. Other literature reported benefits of a pharmacist home visit service such as patient satisfaction, improved medication appropriateness, increased persistence with warfarin therapy, and increased medication discrepancy resolution. Current perspectives to consider in establishing or evaluating clinical pharmacy services offered in a home care setting include: staff competency, ideal target patient population, staff safety, use of technology, collaborative relationships with other health care providers, activities performed during a home visit, and pharmacist autonomy.
\end{abstract}

Keywords: clinical pharmacy, home care, home visit, medication review, pharmacist

\section{Introduction}

Over the past several decades, the scope of clinical pharmacy services has expanded both in terms of skills and areas in which services are offered. Traditionally, the availability of clinical pharmacy services has been in the purview of hospitals where increased clinical pharmacy services has been associated with reduced length of stay and mortality. ${ }^{1}$ Recognition of the value of the role of the pharmacist has resulted in expansion of clinical services into outpatient settings, including patient homes. For example, the Home Medicines Review (HMR) program that was established in Australia in 2001 provides funding for pharmacists to visit patients at home to assess their medication regimens. ${ }^{2}$ In Canada, provincial governments are compensating pharmacists for providing medication reviews (MRs) for non-hospitalized patients ${ }^{3}$ and also authorizing pharmacists to prescribe. ${ }^{4}$

While there is evidence to suggest that pharmacist prescribing activities can improve patient outcomes in outpatient settings, ${ }^{5-7}$ the evidence to support the benefit of MRs in outpatient settings is equivocal. Holland et al conducted a systematic review and meta-analysis to evaluate the impact of pharmacist-led MR in older adults and reported that there was no effect on reducing mortality or hospital admissions, but that the intervention may reduce the number of prescribed drugs and improve 
drug knowledge and adherence. ${ }^{8}$ More recently, an evaluation of the MR service available in the province of British Columbia, Canada, reported that there had been little impact on prescription drug use in the province as a result of this program. ${ }^{9}$ In contrast, a systematic review and meta-analysis that evaluated medication reconciliation programs at hospital transitions and included pre- and post-discharge pharmacist visits reported significantly reduced adverse drug event (ADE)-related hospital revisits attributable to the interventions, which included pharmacist home visits (HVs). ${ }^{10} \mathrm{~A}$ recent randomized-controlled trial (RCT) determined that an extended intervention that included both a pharmacistled pre-hospital discharge MR and post-discharge follow-up significantly reduced readmissions within 30 or 180 days compared with usual care; however, the MR alone did not. ${ }^{11}$

These studies were not focused solely on clinical pharmacy services in home care and so applicability to this setting is limited. A review of clinical pharmacy services offered in the home concluded that more rigorous evaluation is needed to support the value of these services and highlighted that questions remain about optimal practice models and target patient populations. ${ }^{12}$ In our health authority, home care clinical pharmacy services have matured to the point where they are an established component of home care in locations where they are available, with ongoing requests for more. The maturation of these services has seen the pharmacist involved in increasingly more aspects of home care services, beyond what was initially supported by evidence. ${ }^{13}$ Determining best practices for clinical pharmacy services offered in the home, as well as other settings, is important to guide practice that will ensure maximum patient benefit. Furthermore, changes in technology, patient and provider experience, safety, and expectations for pharmacy services are possible influencers of how services are delivered or valued.

The purpose of this review is to identify outcomes associated with clinical pharmacy services provided in the home, as well as to describe current perspectives of practice described in the literature.

\section{Literature search}

Two separate literature searches were undertaken to identify articles published for the time period from January 2007 to December 2017. This time frame was chosen to follow up on a previous review published in 2008. ${ }^{12}$ Using the key terms "Pharmacist" and "home visit", EMBASE, Medline, OVID, CINAHL, Biomedical Reference Collection, EBMR, and Google Scholar were searched. The search was limited to the citations published in the English language and involved human subjects. Additionally, the gray literature and reference lists of articles found were searched for additional records. One hundred and fifty-six unique records were found, of which 54 were excluded as they were conference abstracts or the full article access was not possible. In addition, a further 27 were excluded as they did not describe pharmacists doing HVs in a unique study published in 2007 or onward, leaving 75 articles that were included in this review.

Different programs and authors use different terminology to refer to similar concepts. We will be referring to medication reconciliation (MRec) as the act of comparing all medication lists in order to reconcile and create a master list of what the patient should be taking. MR refers to the act of compiling a list of medications the patient is taking and assessing the appropriateness of each medication and the regimen as a whole. MRec may be included in the process of MR. We will refer to medication, therapy, or drug-related problems as drug-related problems (DRPs).

\section{Evaluation of pharmacist home visit initiatives}

Pharmacist HV initiatives in 11 countries were found described in the literature: Australia, Brazil, Canada, Japan, Jordan, the Netherlands, New Zealand, Singapore, Thailand, the UK, and the USA.

\section{Randomized-controlled trials}

The nine RCTs and two cost-effectiveness analyses of pharmacist HV initiatives are outlined in Table $1 .{ }^{14-25}$ In general, the programs included those older than 60 years and who were expected to be at increased risk of medication misadventure. Five studied patients being discharged from hospital ${ }^{14,16,18,19,22}$ and four recruited from outpatient settings. ${ }^{15,20,23,24}$ Souter et al recruited from both an inpatient and outpatient setting. ${ }^{25}$ Additional eligibility criteria used to define the target study population included number of medications ( $\geq 2$ to $\geq 5$ ); functional decline, frailty, or disease-specific (CHF/stroke). Six of the studies described the qualifications of the pharmacists conducting the intervention, indicating training or experience beyond an entry to practice degree. ${ }^{14-16,18,19,23}$

Two studies reported reduced health care utilization attributable to the pharmacist HV intervention: reduced prescribed medications ${ }^{15}$ and reduced non-heart failure hospital days. $^{22}$ The cost-effectiveness analyses of the Anticipatory and Preventative Team Care (APTcare) trial and the HOMER trial (published in 2005) did not support cost-effectiveness of the pharmacist HVs. ${ }^{16,17,21}$ The HOMER trial intervention group experienced significantly increased emergency 


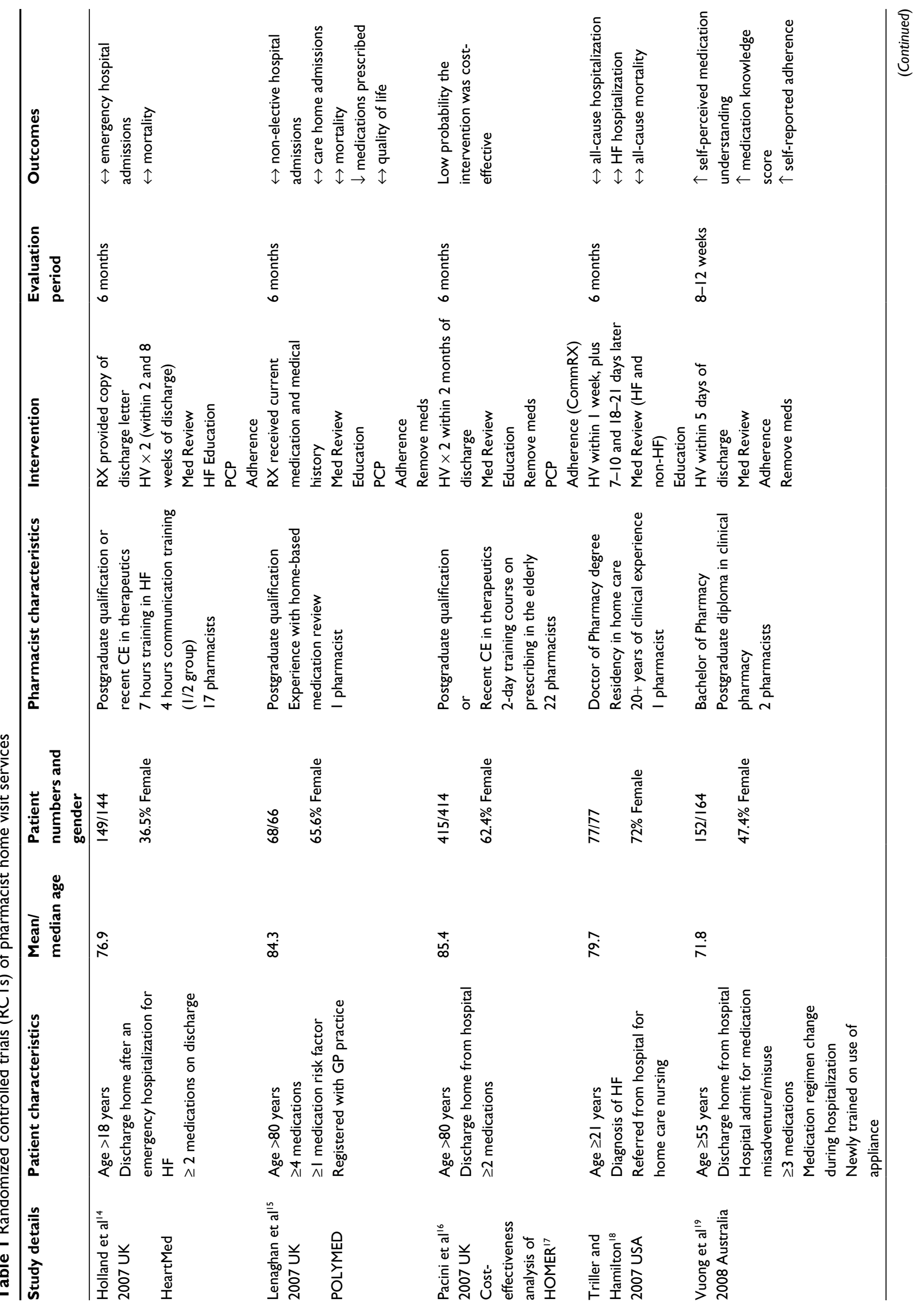




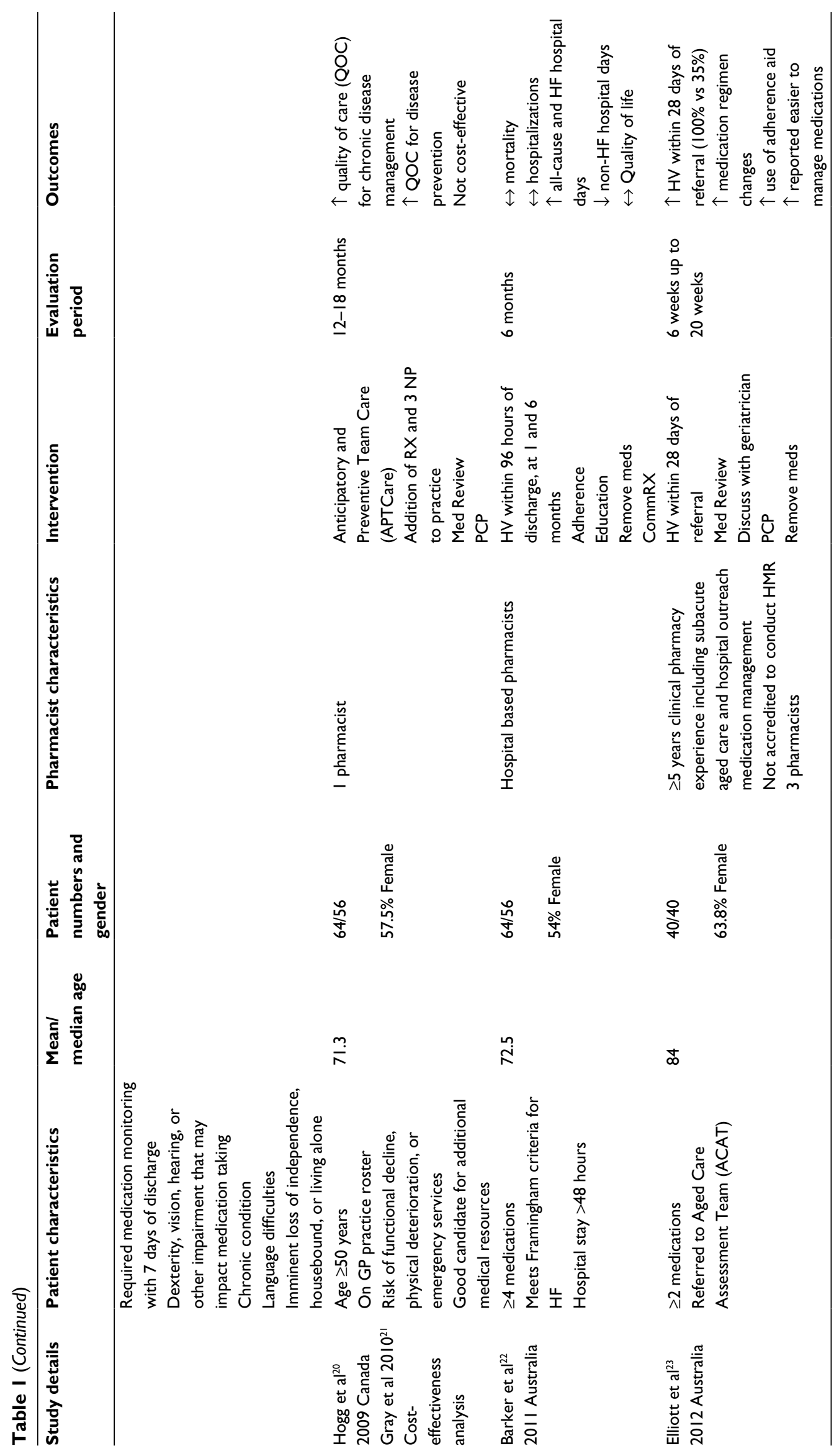




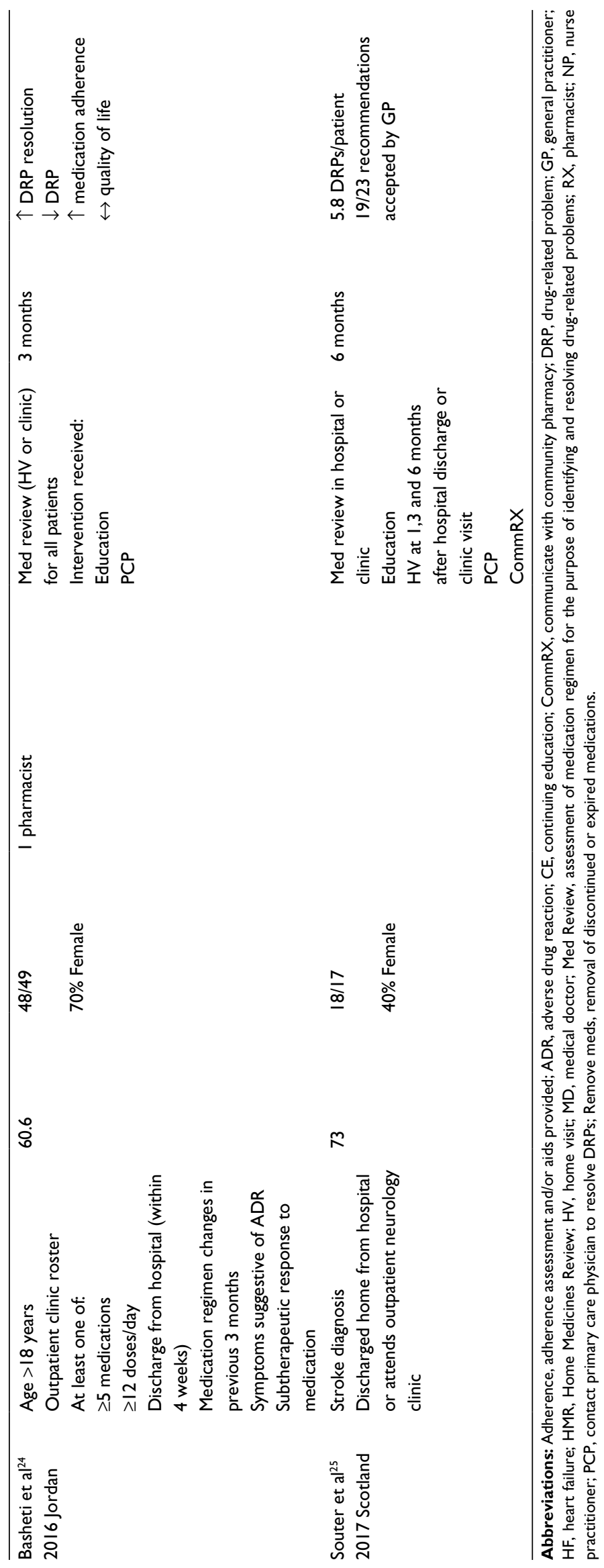


readmissions. ${ }^{17}$ APTcare, a multidisciplinary collaboration focused on patients with chronic disease, despite providing increased quality of care was not cost-effective, this may have been reflective of it being in the implementation stage, rather than established. ${ }^{16,17}$

The clinical outcomes reported from these RCTs indicated that these programs can improve medication understanding, knowledge, and adherence and result in increased resolution of DRPs. No benefit on quality of life was reported.

While not all of the RCTs evaluated economic outcomes, it is hard to explain the limited impact of the pharmacist interventions on health care costs. The interventions undertaken in these trails all appeared to involve pharmacists conducting MR for the purpose of identifying DRPs with subsequent communication to a physician. What is unclear is the depth of the medication regimen assessment, for example, were the recommendations in line with evidence to support reducing morbidity and mortality? Also, the acceptance of recommendations made by the pharmacist was not always reported. Moreover, the extent of access the pharmacists had to medical and laboratory information was sometimes limited and may not have allowed for a comprehensive MR. ${ }^{14-16,19}$ Maturation of clinical pharmacy services may have occurred over the course of years these studies were undertaken, and later studies appeared to involve pharmacists doing more detailed reviews with greater prescriber collaboration, ${ }^{24,25}$ but did not evaluate economic outcomes. The most recent trial to evaluate economic outcomes was conducted by Barker et al; however, the usual care group received an extensive intervention which may have limited the impact of the study intervention..$^{22}$

Other activities performed by the pharmacists included removing expired or discontinued medications, ${ }^{15,16,18,22,23}$ education, ${ }^{14-16,18,22,24,25}$ and adherence assessment. ${ }^{14-16,18,20,22}$ While these activities alone or together may be of benefit to patients, unless the medication regimen is optimized to ensure maximal efficacy and minimal harm, they might not be enough to significantly improve patient outcomes.

\section{Comparison studies}

The 17 studies using a comparison design for evaluation of a pharmacist HV intervention are outlined in Table 2. ${ }^{26-42}$ The majority of these studies evaluated the pharmacist HV intervention in a population of those recently discharged (acute care or skilled nursing facility). $27-31,33,34,36-38,40,41,42$ Some specified patients from a primary care setting, ${ }^{35,39}$ while two studies sourced patients from administrative claims data. ${ }^{26,32}$

The largest proportion of studies were evaluations of the HMR in Australia. ${ }^{26,30,31-34}$ Through the HMR program, accredited pharmacists are funded to provide home-based MR services for community-based patients at risk of medication misadventure. ${ }^{2}$ In addition to conducting a comprehensive MR, pharmacists provide patients with education, assess and aid in adherence and removal of old medications. A report documenting findings and recommendations must be sent to the patient's physician and community pharmacy.

Most of the other studies were evaluations of pharmacists conducting an $\mathrm{HV}$ intervention similar to the HMR, ${ }^{29,40}$ except that not all reported pharmacists removed expired or discontinued medications. ${ }^{26,35,38,40,42}$ Some authors described a MRec intervention rather than a MR. ${ }^{27,28,41}$

The outcomes evaluated and reported in these studies are outlined in Table 3. In contrast to the RCT data, more of these studies reported reduced health care costs. The exception to this was Hanna et al, who reported an overall increase in hospital admissions; however, when they broke the study population down by age, there was a benefit of reduced hospitalizations among those aged 51-65 years. ${ }^{38}$ Improvements in clinical and humanistic outcomes were also reported in these studies. The difference in impact of the pharmacist interventions on health care costs reported in these studies, compared with the RCTs, may be attributable to study design. The patients and settings were similar, as well as the extent of pharmacist training, to those described in the RCTs. The evaluation time periods in the RCTs were at least 6 months or longer, whereas these studies reported economic benefits over 30 days ${ }^{36,40}$ and at 6 months. ${ }^{35,42}$

\section{Program reports}

Table 4 outlines the 23 articles describing evaluations of clinical pharmacy home care services in which no comparison group was used. ${ }^{43-65}$ The post-hospital discharge patient population was the most represented in these articles. ${ }^{44,46,48,52-54,59,60,63,64}$ Other authors describe programs established in community settings ${ }^{43,47,49,56,58,61,65}$ and clinics. ${ }^{45,50,55,57,62}$ Other patient characteristics included being elderly, presence of a chronic disease, or number of medications.

The majority of these articles describe a program in which a HV was conducted to undertake a MR. ${ }^{43-50,52-65}$ The HVs were typically conducted by a pharmacist, with some authors describing the use of pharmacy technicians, ${ }^{63,64}$ pharmacy students, ${ }^{50}$ pharmacy residents/students accompanying a nurse practitioner ${ }^{57}$ or a pharmacy resident, or a pharmacist. ${ }^{59}$ Onda et al do not specifically describe an intervention; however, a pharmacist-conducted MR is assumed..$^{58}$ These authors sent a survey to pharmacists who conducted HVs, the purpose of 


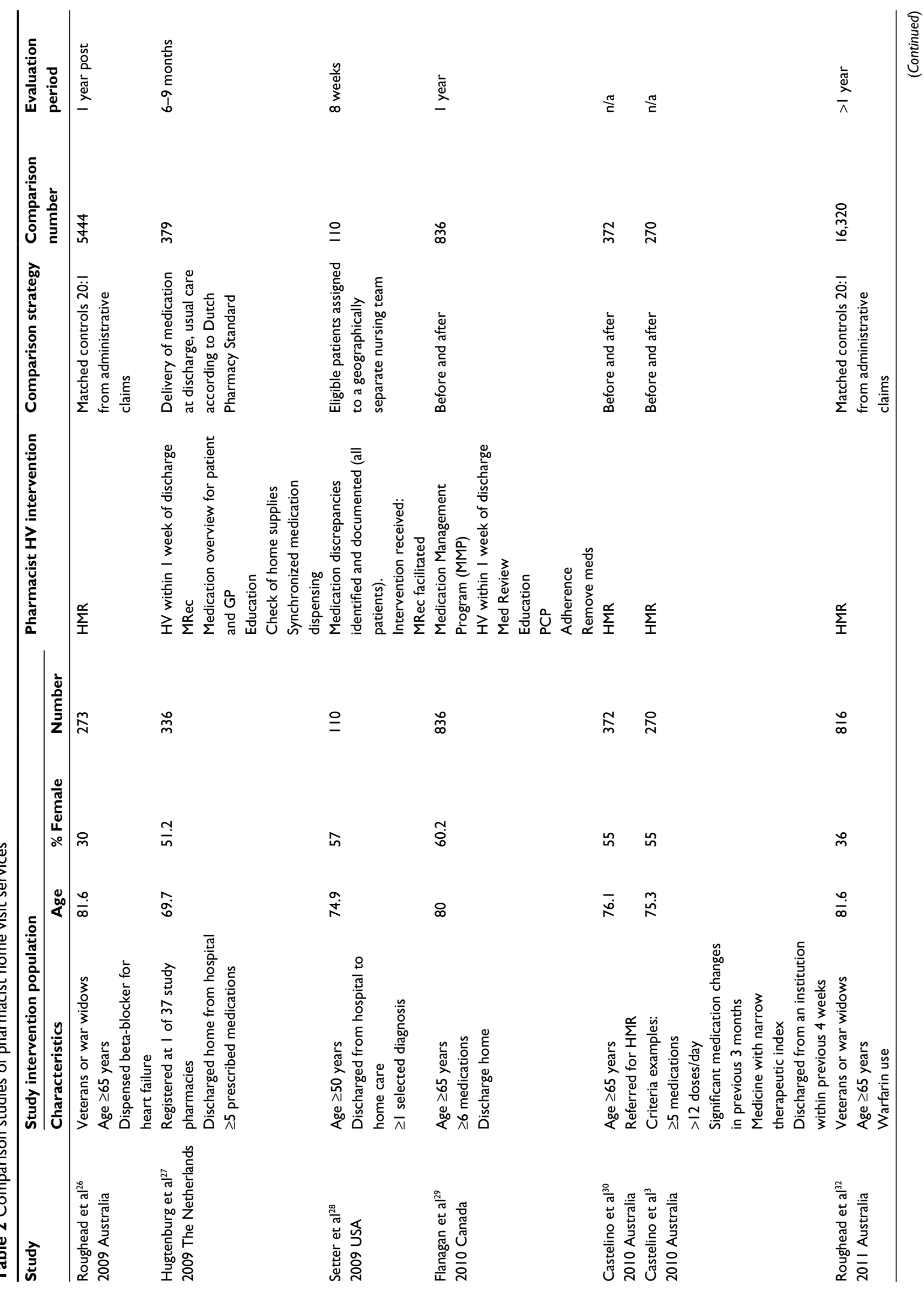




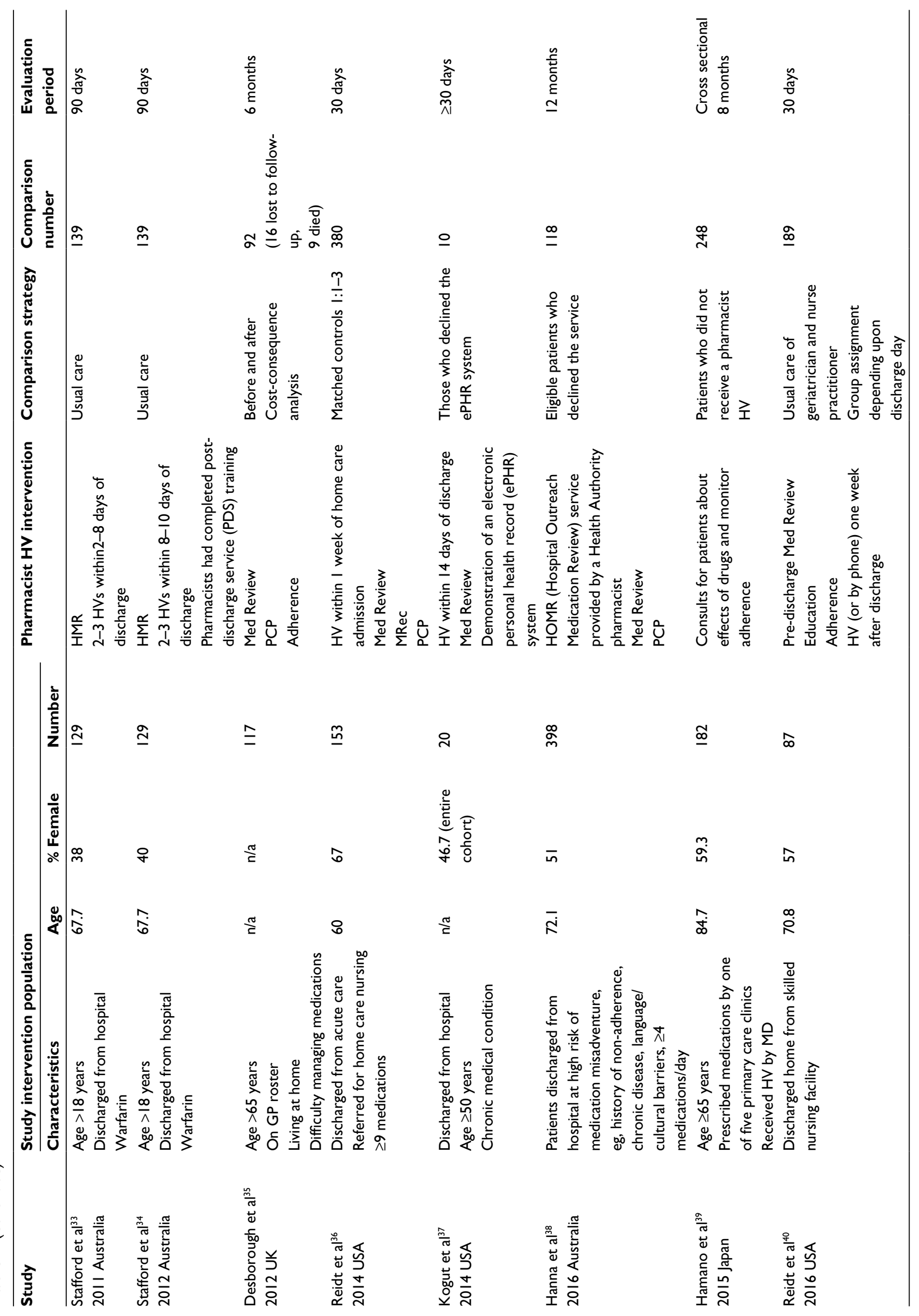




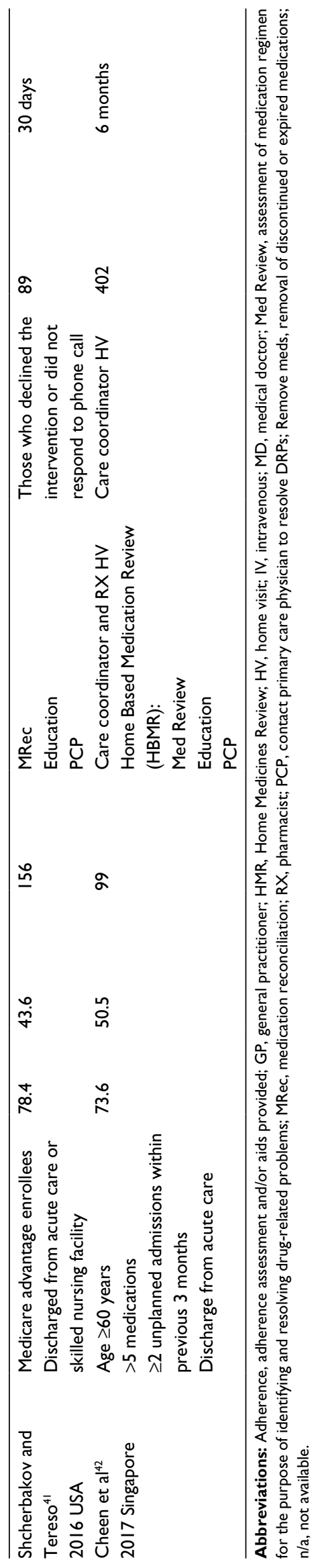

Table 3 Outcomes reported from non-randomized comparison studies

\begin{tabular}{|c|c|}
\hline \multirow[t]{5}{*}{ Economic } & $\downarrow$ Emergency department visits ${ }^{36,40,42}$ \\
\hline & $\downarrow$ Hospitalization ${ }^{26,29,32 a, 35,42}$ \\
\hline & $\uparrow$ Hospitalization ${ }^{38}$ \\
\hline & $\uparrow$ Medication costs ${ }^{39 b}$ \\
\hline & $\downarrow$ Hospital and medication costs ${ }^{35}$ \\
\hline \multirow[t]{8}{*}{ Clinical } & $\downarrow$ Drug Burden Index $(\mathrm{DBI})^{30}$ \\
\hline & $\uparrow$ Medication appropriateness $^{31}$ \\
\hline & $\uparrow$ Medication discrepancy resolution ${ }^{28}$ \\
\hline & $\uparrow$ Oral anticoagulation knowledge $(\mathrm{OAK})^{34 \mathrm{c}}$ \\
\hline & $\downarrow$ Major and minor hemorrhagic events ${ }^{33}$ \\
\hline & $\uparrow$ Warfarin persistence ${ }^{33}$ \\
\hline & $\uparrow$ Medication adherence $\mathrm{e}^{35}$ \\
\hline & $\uparrow \mathrm{DRP}$ identification ${ }^{36}$ \\
\hline Humanistic & $\uparrow$ Satisfaction ${ }^{27,37 d, 41 d}$ \\
\hline
\end{tabular}

Notes: aFor the time period 2-6 months after RX intervention. No difference for $<2$ months, 6-12 months; Thospitalization $>12$ months. 'Significantly higher costs of potentially inappropriate medications (PIMs) compared to those who received a home visit from a nurse and no pharmacist home visit. 'Significantly higher than usual care at 8 days post-intervention, but not at 90 days. ${ }^{\circ}$ For intervention group only. Abbreviations: DRP, drug-related problem; RX, pharmacist.

which was to determine the prevalence of ADEs and potentially inappropriate medication use among the population.

The impact of the HV programs described in these reports were mainly related to identification of DRPs, recommendations made, or medication changes that occurred as a result of the pharmacist's actions. ${ }^{44-50,53,55,62-65} \mathrm{~A}$ variety of other impacts were also reported: satisfaction, ${ }^{43,44,48,52,54,60}$ time reduction for other disciplines, ${ }^{45} \mathrm{ADE}$ identification, ${ }^{47,58}$ perceptions of program, ${ }^{51}$ experience, ${ }^{61}$ adherence, ${ }^{56,59}$ clinical parameters, ${ }^{55,56}$ and knowledge..$^{48,56,60,61}$ Three programs reported economic outcomes including reduced readmission rate $^{52,59}$ and cost-avoidance. ${ }^{63}$

\section{National surveys}

Five nationwide surveys evaluating pharmacist HV services were identified ${ }^{66-70}$ An evaluation of general practitioner (GP) engagement in HMR in Australia received 376 (33\%) respondents, of which 180 had participated in HMR. ${ }^{66}$ The authors reported that of those who had participated in the HMR, over half did not provide written feedback on the HMR report to the pharmacist or discuss it with the pharmacist. Further, only $10.6 \%$ provided the pharmacists with patient information such as recent laboratory results and $6.7 \%$ accepted the pharmacist's recommendations, yet over half agreed or strongly agreed that the HMR benefits their patients.

A Canadian survey received 17 responses from pharmacists who provided HVs ${ }^{67}$ Services provided include: medication reconciliation, adherence assessment, education for 
Table 4 Program evaluations of clinical pharmacy home visit services

\begin{tabular}{|c|c|c|c|}
\hline Study & Patient characteristics & Service description & Evaluation details \\
\hline Moultry and & Isolated, elderly needing assistance & HV I5-60 minutes & 30-item survey completed by $18 / 30$ \\
\hline Poon $^{43}$ & managing medications & Med Review & $96 \%$ felt knowledgeable about medications \\
\hline \multirow[t]{7}{*}{2008 USA } & Referred by community agency & $\mathrm{MRec}$ & after $\mathrm{HV}$ \\
\hline & $\mathrm{N}=30$ recipients over I year & Education emergency preparedness & $73 \%$ felt $\mathrm{HV}$ would reduce visits to $\mathrm{MD}$ \\
\hline & & Disaster proof medication storage & $94 \%$ satisfied/somewhat satisfied \\
\hline & & Remove meds & $100 \%$ would recommend program to others \\
\hline & & Documentation: action plan with & \\
\hline & & DRPs to take to MD & \\
\hline & & Referral to other services as needed & \\
\hline \multirow{13}{*}{$\begin{array}{l}\text { MacAulay et al }{ }^{44} \\
2008 \text { Canada }\end{array}$} & Discharged from hospital to home care & $\mathrm{HV}$ on average $1 \mathrm{I} .7$ days after hospital & 98 DRPs: 3.6 DRPs/patient \\
\hline & and one of the following: & discharge & $\downarrow D R P s$ from visit \#I to visit \#2 \\
\hline & Age $\geq 80$ years & Follow-up HV or by telephone & II6 recommendations: 4.3 \\
\hline & $\geq 5$ medications & Med Review & recommendations/patient \\
\hline & Use of high risk medication & Adherence & Recommendation significance \\
\hline & Chronic condition & Education & $17 \%$ very significant \\
\hline & Suboptimal adherence & PCP & $71 \%$ significant \\
\hline & Benefit from medication education & & II\% somewhat significant \\
\hline & Medication changes during hospitalization & & Satisfaction survey $(n=16)$ \\
\hline & Unresolved DRPs at discharge & & Overall satisfaction $9.9 / 10$ \\
\hline & $\mathrm{N}=27$ & & Importance of HV 9.8/10 \\
\hline & Average age $=81.1$ years & & Usefulness of HV 9.5/10 \\
\hline & $67 \%$ Female & & \\
\hline Stell et a $\left.\right|^{45}$ & Outpatient Disease Management Unit & Med Review & 20 medication recommendations \\
\hline 2008 Australia & $\begin{array}{l}\text { Referrals to } R X \text { from unit coordinator } \\
\text { for those who may benefit from } R X \\
\text { review } \\
\text { eg, patients taking multiple medications } \\
\text { they organized themselves, new patients, } \\
\text { available patients } \\
\mathrm{N}=24 \text { patients received HV } \\
\text { Average age }=79 \text { years } \\
42 \% \text { Female }\end{array}$ & PCP & $\begin{array}{l}\text { I7 medication issues identified for further } \\
\text { clinician review } \\
\mathrm{N}=34 \mathrm{MD} \text { responses } \\
\text { Perceived medication list more accurate } \\
\text { when completed by } \mathrm{RX} \\
\downarrow \text { Time for other clinicians to obtain } \\
\text { medication list } \\
5.4 \text { minutes/patient not seen by } R X \text { vs } 1.8 \\
\text { minutes/ patient seen by } R X\end{array}$ \\
\hline Flanagan et $\mathrm{al}^{46}$ & Age $\geq 65$ years & Medication Management Program (MMP) & 259 DRPs: median 2 DRPs/patient \\
\hline \multirow[t]{6}{*}{2010 Canada } & $\geq 6$ Medications & HV within I week of discharge & I35 Medication discrepancies: median I \\
\hline & Discharge home & Med Review & discrepancy/patient \\
\hline & $\mathrm{N}=110$ & Education & \\
\hline & Average age $=84$ years & Adherence & \\
\hline & $56 \%$ Female & PCP & \\
\hline & & Remove meds & \\
\hline $\begin{array}{l}\text { Eichenberger } \\
\text { et } \mathrm{a}^{47}\end{array}$ & $\begin{array}{l}\text { Medication history available at } \\
\text { community pharmacy ( } n=79 \text { pharmacies) }\end{array}$ & $\begin{array}{l}76 \mathrm{HVs} \text { by students } \\
\text { Med Review }\end{array}$ & $\begin{array}{l}\text { 7.4 DRPs/patient identified vs } 3.6 \mathrm{DRPs} / \\
\text { patient if } \mathrm{HV} \text { not conducted }\end{array}$ \\
\hline \multirow[t]{9}{*}{2011 Switzerland } & with fifth year pharmacy master student & Adherence & Experience of an ADE \\
\hline & interns & Recommendations summarized for & $19(86.4 \%)$ of transplant patients \\
\hline & $\mathrm{N}=54$ Diabetic and age $\geq 60$ years & supervising RX who could decide on & $26(48.1 \%)$ of diabetes patients \\
\hline & Average age $=71.4$ years & intervention & \\
\hline & $37 \%$ Female & & \\
\hline & $\mathrm{N}=22$ Transplant patient and age $\geq 18$ & & \\
\hline & years & & \\
\hline & Average age $=52.6$ years & & \\
\hline & $50 \%$ Female & & \\
\hline Hussainy et $\mathrm{al}^{48}$ & Patients referred to palliative care & HMR & $\mathrm{N}=422$ \\
\hline \multirow[t]{5}{*}{2011 Australia } & (medication screening by pharmacist) & Ensuring medication access & $\mathrm{N}=52 \mathrm{HV}$ \\
\hline & Patients discharged home from hospital: & Team member education & average 54.4 minutes \\
\hline & hospital visit prior to discharge and $\mathrm{HV}$ & & $\mathrm{n}=1 \mid 3$ DRP interventions \\
\hline & $7-10$ days thereafter or $\mathrm{HV}$ if from a & & $\mathrm{n}=120$ recommendations \\
\hline & different hospital & & \\
\hline
\end{tabular}


Table 4 (Continued)

\begin{tabular}{|c|c|c|c|}
\hline Study & Patient characteristics & Service description & Evaluation details \\
\hline & & $\begin{array}{l}\text { Consult and collaboration with team } \\
\text { Liaison with other health providers } \\
\text { (continuity of care) } \\
\text { Implementation through education } \\
\text { of symptom management protocol } \\
\text { (education) }\end{array}$ & $\begin{array}{l}\text { Survey } n=20 / 32(63 \%) \text { response } \\
100 \% \text { role was helpful } \\
90 \% \text { improved medication knowledge } \\
60 \% \text { changed practice } \\
95 \% \text { more likely to discuss medication } \\
\text { issues with the pharmacist }\end{array}$ \\
\hline $\begin{array}{l}\text { Castelino et a }{ }^{49} \\
20 \text { II Australia }\end{array}$ & $\begin{array}{l}\text { Age } \geq 65 \text { years } \\
\text { HMR conducted by seven accredited } \\
\text { pharmacists } \\
N=224 \\
\text { Average age }=74.6 \text { years } \\
53 \% \text { Female }\end{array}$ & HMR & $\begin{array}{l}\text { III } 0 \text { DRPs: Average } 4.9 \text { DRPs/patient } \\
\text { III } 4 \text { recommendations to GP } \\
964 \text { recommendations required evidence } \\
\text { support; } 94 \% \text { evidence based }\end{array}$ \\
\hline $\begin{array}{l}\text { Willis et a }{ }^{50} \\
201 \text { I USA }\end{array}$ & $\begin{array}{l}\text { Age } \geq 65 \text { years } \\
\text { Registered at primary care } \\
\mathrm{N}=118\end{array}$ & $\begin{array}{l}\text { Undergraduate pharmacy students } \\
\text { performing } \mathrm{HV}, \mathrm{n}=75 \\
\text { Activities: } \\
\text { Best possible medication history } \\
\text { Falls risk evaluation } \\
\text { Blood pressure check } \\
\text { Reviewed by pharmacist afterwards }\end{array}$ & $\begin{array}{l}57(48 \%) \text { patients had a change in therapy } \\
102(86 \%) \text { prescribed a falls risk medication }\end{array}$ \\
\hline $\begin{array}{l}\text { White and } \\
\text { Klinner }^{51} \\
2012 \text { Australia }\end{array}$ & $\begin{array}{l}\text { Chinese and Vietnamese immigrants } \\
\text { eligible for, but who have not received } \\
\text { HMR } \\
\mathrm{N}=17 \text { ( } 6 \text { Chinese, II Vietnamese) }\end{array}$ & No RX HV or intervention & $\begin{array}{l}\text { Two focus groups to assess perceptions of } \\
\text { HMR among immigrants } \\
\text { Had not heard of HMR, but welcomed it } \\
\text { Concern that HMR would upset MD or lack } \\
\text { of cooperation } \\
\text { Concerns and confusion about medicines } \\
\text { RX role is medicine supply } \\
\text { GP role is medication decisions } \\
\text { Neither GP nor RX helpful in responding to } \\
\text { detailed medication questions } \\
\text { Difference between ethnicities in trust for } \\
\text { MD } \\
\text { Language barrier for accessing medication } \\
\text { information }\end{array}$ \\
\hline $\begin{array}{l}\text { Novak et al }{ }^{52} \\
2012 \text { USA }\end{array}$ & $\begin{array}{l}\text { Medicare patients recently discharged } \\
\text { from acute or subacute care } \\
\text { High risk for readmission, eg, multiple } \\
\text { chronic conditions, multiple medications, } \\
\text { multiple hospitalizations in the previous } \\
12 \text { months }\end{array}$ & $\begin{array}{l}\text { Pharmacist Care Manager (PCM) } \\
\text { HV 2-3 hours followed by at least } \\
\text { weekly telephone calls } \\
\text { Med Review } \\
\text { MRec } \\
\text { Adherence } \\
\text { Education } \\
\text { Assessment of falls risk, cognition, } \\
\text { mental health, nutrition and caregiver } \\
\text { needs } \\
\text { PCP }\end{array}$ & $\begin{array}{l}30 \% \text { reduction in readmissions } \\
\mathrm{PCM} \text { job satisfaction }\end{array}$ \\
\hline Kwint et $\mathrm{a}^{53}$ & Age $\geq 65$ years & $\mathrm{HV}$ conducted by trained community & DRPs \\
\hline 2012 The & $\geq 5$ oral medications & pharmacists & I565 (I0/patient) DRPs based on pre-visit \\
\hline Netherlands & $\begin{array}{l}\text { Discharge from hospital } \\
\text { Use one of } 10 \text { community pharmacies } \\
\mathrm{N}=155 \\
\text { Median age }=76 \text { years } \\
54 \% \text { Female }\end{array}$ & $\begin{array}{l}\text { Med Review adjusted and completed } \\
\text { by two independent reviewers } \\
\text { pharmacists. Reviewer pharmacists } \\
\text { prioritized DRPs and sent back to } \\
\text { pharmacists to discuss with MD within } \\
4 \text { weeks }\end{array}$ & $\begin{array}{l}\text { review } \\
4 \text { I } 5 \text { DRPs identified through HV } \\
905(58 \%) \text { DRPs resulted in a } \\
\text { recommendation } \\
264 / 905(29 \%) \text { recommendations } \\
\text { implemented } \\
\text { DRPs identified during HV more likely to } \\
\text { have a higher priority and recommendations } \\
\text { implemented }\end{array}$ \\
\hline
\end{tabular}


Table 4 (Continued)

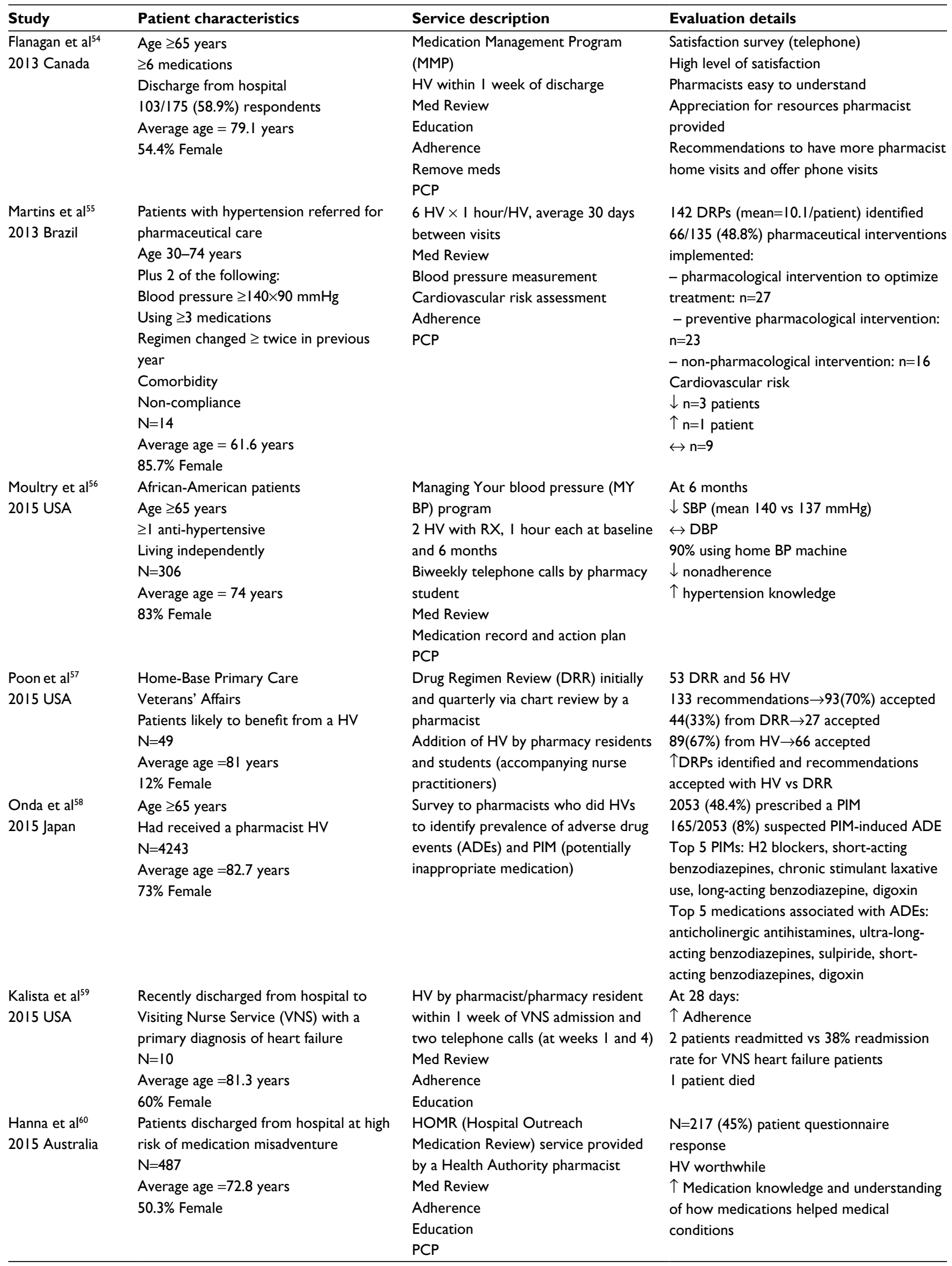


Table 4 (Continued)

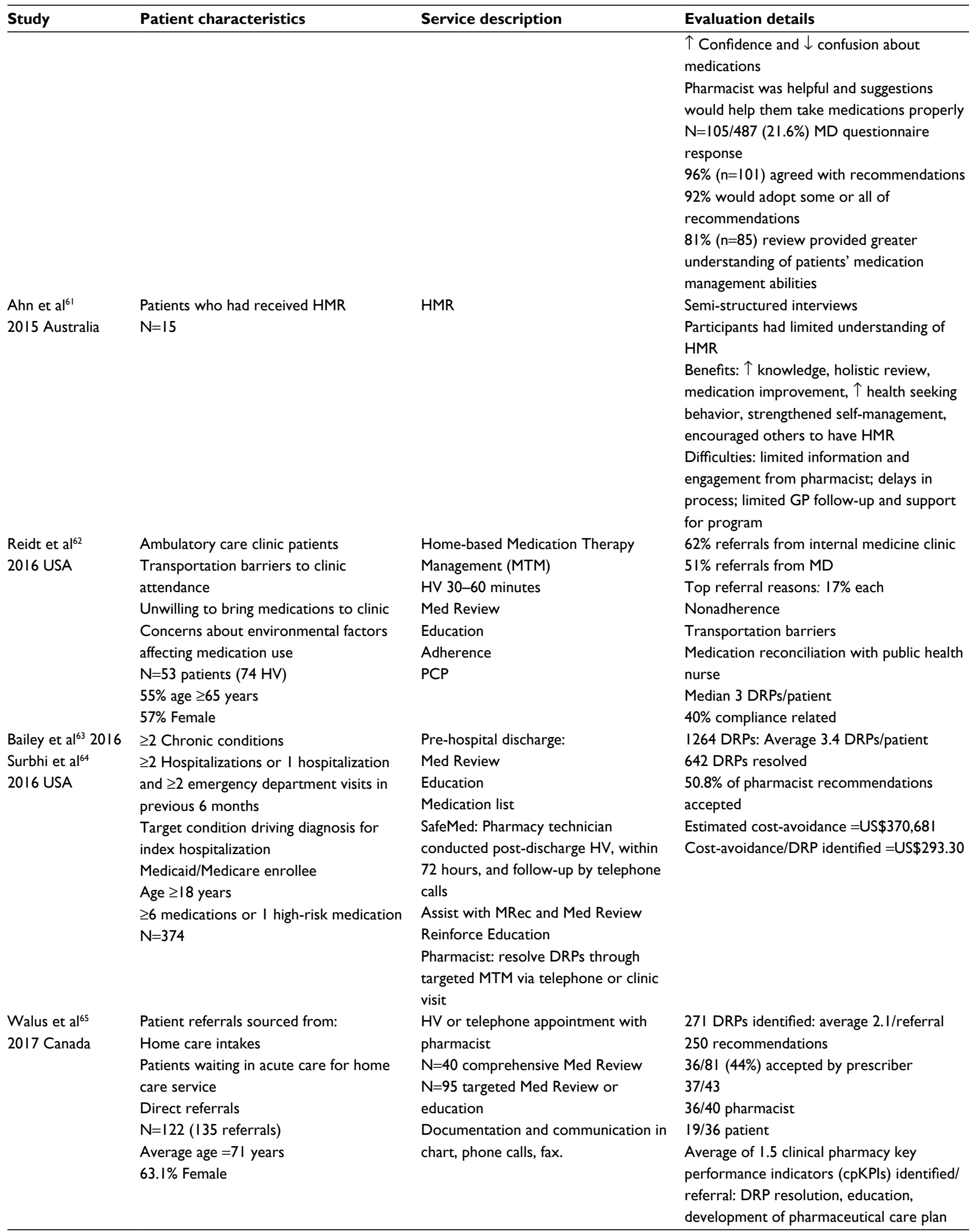

Abbreviations: Adherence, adherence assessment and/or aids provided; DRP, drug-related problem; GP, general practitioner; HV, home visit; MD, medical doctor; Med Review, assessment of medication regimen for the purpose of identifying and resolving drug-related problems; MRec, medication Reconciliation; RX, pharmacist; PCP, contact primary care physician to resolve DRPs; Remove meds, removal of discontinued or expired medications; HMR, Home Medicines Review; ADE, adverse drug event. 
patients/caregivers and health professionals, chronic disease monitoring, and assessing acute health concerns. None of the programs was government funded, and three of the pharmacists reported charging a private home care agency for their services. Facilitators for HVs identified in the survey were referrals from physicians and support from management. The barriers cited by respondents were insufficient remuneration and lack of time for completing visits.

A similar survey undertaken among British pharmacists received 247 respondents (81.5\% response rate). ${ }^{68}$ The authors reported that $74 \%$ of respondents had specific but undefined training, and $81 \%$ of the services were funded through Primary Care Trusts. HV services operational beyond a year were those that included social services, GPs, and community nurses in the service protocol of operations and those that received more of their referrals from GPs (90\% vs 50\%).

Patient preference for medication therapy management was evaluated in Thailand. ${ }^{69}$ Based on the 265 respondents, the authors reported that patients valued this service and preferred pharmacist visits to occur in the pharmacy rather than their home and that the preferred visit length was 20 minutes rather than 1 hour.

In the Netherlands, an evaluation of implementing a HV service to patients after hospital discharge was undertaken using a focus group ( 22 pharmacists) to identify barriers and facilitators, followed by a survey (20 pharmacist respondents) to score the relevance and feasibility of items identified during the focus groups. ${ }^{70}$ The pharmacists included in this evaluation conducted on average $5.4 \mathrm{HVs} /$ year. The authors reported that both the need for reimbursement and the readiness of community pharmacy to adapt daily routines to implement such a service as two barriers to implementation.

\section{Current perspectives}

In addition to the aforementioned reports, 18 articles describing clinical pharmacy services in a home care setting were identified in the literature. ${ }^{71-88}$ In these reports, the pharmacist $\mathrm{HV}$ intervention was not evaluated. The following section highlights some current perspectives based on these articles, together with those articles previously described that provided an evaluation of clinical pharmacy HV services.

\section{Competency}

Training and qualifications for pharmacists, pharmacy residents and students, and pharmacy technicians involved in HV programs varied. The HMR program in Australia requires pharmacists to be accredited. ${ }^{2}$ In some initiatives training was provided to pharmacists, pharmacy students, or pharmacy technicians who would be providing the service. ${ }^{14-16,33,35,41,42,50,51,53}$ In other reports, background education or experience of the pharmacists was mentio ned. ${ }^{14-16,18,19,22,23,38,42,45,60,72,73}$ No comparison was done at the level of qualifications, experience, or training to outcomes. In our health authority, the pharmacists working in a home care setting as part of the Medication Management Program (MMP) must have completed an Accredited Canadian Pharmacy Residency or equivalent in order to be hired. They receive orientation on conducting $\mathrm{HVs}$ and documentation thereafter.

Use of pharmacy students, residents, and pharmacy technicians highlights the use of resources to both provide learning opportunities and also extend the scope of clinical pharmacy services.

Competency of personnel to provide the service influences the extent to which DRPs and issues preventing patients from achieving optimal health can be identified and resolved. It includes clinical knowledge about disease states and drug therapy and the ability to communicate to extract and provide information.

\section{Patients}

The most commonly studied patient population was patients who had recently been discharged from hospital. ${ }^{14,16,18,19,22,24,25,27-29,33,34,37,38,41,42,44,46,48,52,54,59,60,62,63,74-76}$ Heart failure was the most commonly mentioned diagnosis. ${ }^{14,16,18,22,26,59,74,77}$ While HVs can be more convenient, not all patients may want or need a HV MR. ${ }^{69}$ Furthermore, they may have preferences for how long it should take. ${ }^{69} \mathrm{Sev}-$ eral authors commented on the length of time spent at a HV, ranging from 15 minutes to 2 hours. ${ }^{14,19,29,37,38,43,47,48,55,56,59,74,78}$ In addition to $\mathrm{HV}$ time, travel time must be considered and these together can prevent HVs from being a broadly available service and highlight the need to restrict the service to those for whom it is necessary.

Several authors reported an increased identification of DRPs as a result of a HV compared with medication list review $^{47}$ or chart review ${ }^{53,57}$ and that the DRPs identified during a HV may be more likely to result in a medication change. ${ }^{24,28,64}$ Patients included in these studies were those who might be expected to have many medications: diabetes, ${ }^{47}$ transplant, ${ }^{47}$ older patients, ${ }^{57}$ and older patients discharged from hospital. ${ }^{53}$ Poon et al identified veterans who were likely to benefit from a HV service; however, they do not further articulate this criteria. ${ }^{57}$ Age was often a consideration in the articles included in this review and may impact the outcome; although this was reported by Hanna et al, the numbers in 
each age group were too small to make conclusions about the impact of age. ${ }^{38}$ Vuong et al described inclusion criteria indicative of frailty in their study that selected individuals beyond age, number of medications, and discharge from hospital. ${ }^{19}$ Frailty may be a criteria to use in deciding for whom outpatient clinical pharmacy services be delivered, including HVs, as medications can impact both physical and cognitive functioning. ${ }^{89}$

\section{Safety}

Safety for pharmacists conducting HVs was discussed in five articles. ${ }^{36,60,76,79,80}$ Safety strategies reported include: conducting HVs in pairs; ${ }^{76}$ texting to inform of arrival and departure times ${ }^{76}$ calling patients not previously met prior to arrival; ${ }^{80}$ and wearing a uniform or badge ${ }^{80}$ Pre-screening of patients with a safety risk assessment was described, with those patients believed to be a safety risk to staff ineligible for a $\mathrm{HV} .{ }^{60}$ Similarly, in our health authority, a pre-visit telephone risk assessment screen is conducted, with follow-up items to be assessed during the HV. Depending upon the risk identified and whether or not it can be mitigated for the $\mathrm{HV}$, either staff do not conduct the HV or conduct it with a security personnel.

As patients for whom HVs are provided are typically more frail, staff safety may be overlooked in HV initiatives. However, the safety of the neighborhood, the residence, the presence of pets and other inhabitants, as well as patient/ caregiver/cohabitant illness and recreational drug use must also be considered.

\section{Technology}

Ten articles discussed the use of technology to aid in pharmacist HVs. $27,36,37,40,50,62,74,76,81,83$ The majority described using an electronic medical record (EMR) as a way for the pharmacist to get information about the patient's medical conditions and/or communicate with the primary care provider. ${ }^{27,36,40,50,62,74,76,81}$ Access to medical records, whether EMR or not, is essential to aid a pharmacist to better assess a medication regimen. ${ }^{12}$ The use of an electronic personal health record (ePHR) that allows patients or caregivers to maintain medical information and a medication list and exchange this information with health professionals was reported to result in identification of DRPs in significantly more patients during a $\mathrm{HV}$ compared to patients who did not use the ePHR. ${ }^{37}$ Use of a clinical information system to assess patient genomics and support a pharmacist's assessment of drug interactions among home care clients resulted in significantly reduced re-hospitalizations compared to those whose drug interactions were assessed using clinical judgment and a drug information resource. ${ }^{82}$ This RCT was not an evaluation of a pharmacist HV service; some HVs were provided, but illustrates a resource that could be used to enhance MR services provided in the home.

Besides the ePHR system, all the technology described was for use by pharmacists prior to and/or after a HV, and the need for Internet connectivity in patient homes was not discussed. The ePHR system would necessitate patient access to the Internet. Pharmacist access to the Internet at patient homes is an important aspect to consider in expanding the use of technology for HV clinical pharmacy services.

\section{Collaboration}

The majority of HV programs described in the literature involved pharmacists providing the service and connecting with other health care professionals, such as physicians in order to communicate the findings from their assessment and make suggestions for changes. The reported physician acceptance of recommendations varied from $18 \%$ to 95\%. ${ }^{14,18,23,24,28,29,42,44,65}$ The extent to which communication with prescribers occurred or the suggestions for change that were implemented was not always detailed. Furthermore, pharmacist and physician collaboration may not happen, even if it was the expectation of a program. ${ }^{66}$ Authors of an evaluation of pharmacist recommendation implementation and the extent of collaboration between pharmacists and GPs reported on average $50 \%$ (range $17 \%-86 \%$ ) of pharmacist recommendations were implemented in the 12 RCTs included in the review. ${ }^{90}$ Implementation rate was higher with increased presence of elements reflective of collaboration, such as pharmacist with clinical experience; patient's regular pharmacist providing the intervention; sharing of medical records; patient interview by a pharmacist; referral by GP; case conference; formulation of an action plan; and follow-up on actions.

As many of the programs described and evaluated in this review were new initiatives, the time needed for relationship building for collaborative practice with other health care professionals may not have been sufficient to be able to effect changes to patients' medications and consequently health outcomes. Strategies to leverage existing relationships or create the opportunity for relationship building described in the studies include involving community pharmacists in providing HV programs, ${ }^{27,47,53,67}$ inserting a pharmacist as part of a multidisciplinary team, ${ }^{23,42,48,77,81,82}$ or adding the $\mathrm{HV}$ component to an existing clinical pharmacy service. ${ }^{57}$ 
The extent of collaboration can also depend upon the setting from which HV services are offered. Settings identified in the HV literature include: dispensing pharmacy, ${ }^{24,44,53,58,69,71,76,77,78,84}$ home care, ${ }^{28,29,36,46,54,59,65,81,83}$ chronic disease management or specialty service, $23,25,43,45,48,54,62,75,79,82$ institutional transition service, ${ }^{22,37,38,40,42,44,63,64,73,74}$ health care agency, ${ }^{41,52,57,70,72}$ and primary care. ${ }^{15,20,24,35,39,50,55}$ Pharmacists working in health authority or multidisciplinary teams may have more opportunity to establish collaborative relationships; however, collaborative partnerships can also be established in community settings. A downside of HV services being offered from a community pharmacy can be limited time to conduct HVs and lack of funding. ${ }^{65,66,68}$

Several authors described pharmacists providing HV services with other health care providers: paramedics, ${ }^{74}$ nurses,${ }^{28,42}$ social workers, ${ }^{84}$ multidisciplinary teams, ${ }^{36,48,68,77,81}$ and with a nurse practitioner and primary care physician. ${ }^{21,40,85}$ Co-visiting patients with other health care providers is not only an opportunity to strengthen the team relationships but can enhance collaboration at the point of patient care through the opportunity for complementary skill sets. For example, a pharmacist working in a palliative care team reportedly increased medication-related knowledge of team members and patients. ${ }^{48}$

Another important aspect of relationship and collaboration is referral. Receiving referrals from a physician may not only impact the longevity of a HV program, ${ }^{68}$ but also may result in more collaboration for making medication changes through case conferences. ${ }^{15,53,71}$ However, receiving referrals for a pharmacist HV intervention may not occur, despite being recommended. ${ }^{23}$

\section{HV activities}

MR and MRec were the two most commonly reported $\mathrm{HV}$ activities, with education, adherence assessment, and removal of medications no longer used occurring often. Other activities reported less frequently were: pharmacist performing physical assessments; ${ }^{36,50}$ chronic disease monitoring; ${ }^{20,25,50,55,56,67}$ education for lifestyle changes $;{ }^{87}$ falls assessment; ${ }^{50,52}$ and assessment of cognition, ${ }^{52}$ mental health, ${ }^{52}$ nutrition, ${ }^{52}$ and caregiver needs. ${ }^{52} \mathrm{~A} \mathrm{HV}$ is an ideal opportunity to assess many aspects of a patient's health status, balancing that with what is the best use of a pharmacist during the HVs needs to be considered.

\section{Autonomy}

The impact of pharmacists being able to enact their medication recommendations was not reported; rather pharmacists relied on prescriber acceptance of their recommendations. For example, unlike hospital settings where anticoagulation protocols have been established to allow pharmacists to dose adjust warfarin, HMR pharmacists discussed warfarin dosing changes with a physician. ${ }^{73}$ Prescribing authority for pharmacists is likely to impact this. Matthies describes his role conducting HVs to patients discharged from an emergency department and his ability to initiate or alter patients' medications. ${ }^{88}$ His collaboration with a primary care physician and health authority position allows him access to both EMRs, as well as a collaborative working environment. Collaborative working relationships with other health care professionals and access to information necessary to properly assess drug therapy should not be considered less important if pharmacists have prescribing authority.

\section{Limitations}

It is likely that there are more home care clinical pharmacy services occurring than have been reported in the literature and identified for this review. Surveys done in Canada and the UK illustrate the breadth of services available in these jurisdictions; however, individual reports of all services included in the surveys were not found. Furthermore, it is likely that not all publications were found as the two separate literature searches conducted had only 22 citations in common. ${ }^{11,14,15,22,26,27,29,32,39-42,50,59,60,66,67,73,75-78}$ In addition, one evaluation of the MMP, that exists in our health authority, failed to show up in either search. ${ }^{46}$ No comparison to inpatient clinical pharmacy literature was conducted to evaluate whether elements that contributed to positive outcomes in the inpatient setting can or do exist in the HV clinical pharmacy services literature.

\section{Conclusion}

Pharmacist HV services are available in many countries throughout the world. Unlike literature from inpatient settings, the outcomes reported are equivocal, particularly related to the impact of a pharmacist $\mathrm{HV}$ intervention on subsequent health care costs. Mirroring the conclusions of a previous review of clinical pharmacy services in the home, further refinement of how pharmacist HV services should exist is needed, including the patient population ideally served by a HV and a practice model that best contributes to collaborative practice. ${ }^{12}$ Other important elements to consider in both establishing and evaluating a HV program, and which may be applicable to other settings in which clinical pharmacy services are offered, were identified. These include: staff competency, use of technology, staff safety, 
activities to be performed during a clinical pharmacy intervention (eg, HV), and pharmacist autonomy. Consideration of these elements could help to generate further substantiation of the role of pharmacists providing clinical services in a home care setting.

\section{Disclosure}

The authors report no conflicts of interest in this work.

\section{References}

1. Bond CA, Raehl CL, Franke T. Interrelationships among mortality rates, drug costs, total cost of care, and length of stay in United States hospitals: summary and recommendations for clinical pharmacy services and staffing. Pharmacotherapy. 2001;21(2):129-141.

2. Guidelines for pharmacists providing Home Medicines Review (HMR) services: Pharmaceutical Society of Australia Ltd. 2011. Available from: https://www.psa.org.au/download/practice-guidelines/home-medicinesreview-services.pdf. Accessed March 21, 2018.

3. Pammett R, Jorgensen D. Eligibility requirements for community pharmacy medication review services in Canada. Can Pharm J. 2014;147(1):20-24.

4. Law MR, Ma T, Fisher J, Sketris IS. Independent pharmacist prescribing in Canada. Can Pharm J. 2012;145(1):17-23.

5. Tsuyuki RT, Houle SKD, Charrois TL, et al. Randomized trial of the effect of pharmacist prescribing on improving blood pressure in the community: the Alberta clinical trial in optimizing hypertension (RxACTION). Circulation. 2015;132(2):93-100.

6. Tsuyuki RT, Rosenthal M, Pearson GJ. A randomized trial of a community-based approach to dyslipidemia management: pharmacist prescribing to achieve cholesterol targets (RxACT study). Can Pharm J. 2016;149:283-292.

7. Tsuyuki RT, Al Hamarneh YN, Jones CA, Hemmelgarn BR. The effectiveness of pharmacist interventions on cardiovascular risk: the multicenter randomized controlled RxEACH trial. $\mathrm{J} \mathrm{Am}$ Coll Cariol. 2016;67(24):2846-2854.

8. Holland R, Desborough J, Goodyer L, Hall S, Wright D, Loke Y. Does pharmacist-led medication review help to reduce hospital admissions and deaths in older people? A systematic review and meta-analysis. $\mathrm{Br}$ J Clin Pharmacol. 2008;65(3):303-316.

9. Kolhatkar A, Cheng L, Chan FKI, Harrison M, Law MR. The impact of medication reviews by community pharmacists. J Am Pharm Assoc. 2016;56(5):513-520.

10. Mekonnen A, McLachlan A, Brien J. Effectiveness of pharmacist-led medication reconciliation programmes on clinical outcomes at hospital transitions: a systematic review and meta-analysis. BMJ Open. 2016;6(2):e010003.

11. Ravn-Nielsen LV, Duckert M-L, Lolk M, et al. Effect of an in-hospital multifaceted clinical pharmacist intervention on the risk of readmission. JAMA Intern Med. 2018;178(3):375-385.

12. MacKeigan LD, Nissen LM. Clinical pharmacy services in the home. Dis Manage Health Outcomes. 2008;16(4):227-244.

13. Flanagan PS, Briseño-Garzón A, Zed PJ, Strain RM. Safety outcomes with home assessment trial: a mixed-methods evaluation of medication safety in the home care setting. Home Health Care Manag Pract. 2018;30(2):76-82.

14. Holland R, Brooksby I, Lenaghan E, et al. Effectiveness of visits from community pharmacists for patients with heart failure: HeartMed randomised controlled trial. BMJ. 2007;334(7603):1098.

15. Lenaghan E, Holland R, Brooks A. Home-based medication review in a high risk elderly population in primary care--the POLYMED randomised controlled trial. Age Ageing. 2007;36(3):292-297.

16. Pacini M, Smith R, Wilson E, Holland R. Home-based medication review in older people. Pharmacoeconomics. 2007;25(2):171-180.
17. Holland R, Lenaghan E, Harvey I, et al. Does home based medication review keep older people out of hospital? The HOMER randomised controlled trial. BMJ. 2005;330(7486):293.

18. Triller DM, Hamilton RA. Effect of pharmaceutical care services on outcomes for home care patients with heart failure. Am J Health Syst Pharm. 2007;64(21):2244-2249.

19. Vuong T, Marriott J, Kong D, Siderov J. Implementation of a community liaison pharmacy service: a randomised controlled trial. Int $J$ Pharm Pract. 2008;16(3):127-135.

20. Hogg W, Lemelin J, Dahrouge S, et al. Randomized controlled trial of anticipatory and preventive multidisciplinary team care: for complex patients in a community-based primary care setting. Can Fam Physician. 2009;55(12):e76-e85.

21. Gray D, Armstrong CD, Dahrouge S, Hogg W, Zhang W. Cost-effectiveness of anticipatory and preventive multidisciplinary team care for complex patients: evidence from a randomized controlled trial. Can Fam Physician. 2010;56(1):e20-29.

22. Barker A, Barlis P, Berlowitz D, Page K, Jackson B, Lim W. Pharmacist directed home medication reviews in patients with chronic heart failure: a randomised clinical trial. Int J Cardiol. 2012;159(2):139-143.

23. Elliott R, Martinac G, Campbell S, Thorn J, Woodward. M. Pharmacistled medication review to identify medication-related problems in older people referred to an aged care assessment team. Drugs Aging. 2012;29(7):593-605.

24. Basheti I, Al-Qudah R, Obeidat N, Bulatova N. Home medication management review in outpatients with chronic diseases in Jordan: a randomized control trial. Int J Clin Pharm. 2016;38(2): 404-413.

25. Souter C, Kinnear A, Kinnear M, Mead G. A pilot study to assess the practicality, acceptability and feasibility of a randomised controlled trial to evaluate the impact of a pharmacist complex intervention on patients with stroke in their own homes. Eur J Hosp Pharm. 2016;24(2):101-106.

26. Roughead E, Barratt J, Ramsay E, et al. The effectiveness of collaborative medicine reviews in delaying time to next hospitalization for patients with heart failure in the practice setting: results of a cohort study. Circulation: Heart Failure. 2009;2(5):424-428.

27. Hugtenburg J, Borgsteede S, Beckeringh J. Medication review and patient counselling at discharge from the hospital by community pharmacists. Pharm World Sci. 2009;31(6):630-637.

28. Setter S, Corbett C, Neumiller J, Gates B, Sclar D, Sonnett T. Effectiveness of a pharmacist-nurse intervention on resolving medication discrepancies for patients transitioning from hospital to home health care. Am J Health Syst Pharm. 2009;66(22):2027-2031.

29. Flanagan P, Virani A, Baker W, Roelants H. Pharmacists Making house calls: innovative role or overkill?. Can J Hosp Pharm. 2010;63(6): 412-419.

30. Castelino R, Hilmer S, Bajorek B, Nishtala P, Chen T. Drug burden index and potentially inappropriate medications in community-dwelling older people. Drugs Aging. 2010;27(2):135-148.

31. Castelino R, Bajorek B, Chen T. Retrospective evaluation of home medicines review by pharmacists in older Australian patients using the medication appropriateness index. Annals of Pharmacother. 2010;44(12):1922-1929.

32. Roughead E, Barratt J, Ramsay E, et al. Collaborative home medicines review delays time to next hospitalization for warfarin associated bleeding in Australian war veterans. J Clin Pharm Ther. 2011;36(1): 27-32.

33. Stafford L, Peterson GM, Bereznicki LRE, et al. Clinical outcomes of a collaborative, home-based postdischarge warfarin management service. Ann Pharmaother. 2011;45(3):325-334.

34. Stafford L, van Tienen E, Bereznicki L, Peterson G. The benefits of pharmacist-delivered warfarin education in the home. Int $J$ Pharm Pract. 2012;20(6):384-389.

35. Desborough J, Sach T, Bhattacharya D, Holland R, Wright D. A costconsequences analysis of an adherence focused pharmacist-led medication review service. Int J Pharm Pract. 2011;20(1):41-49. 
36. Reidt $\mathrm{S}$, Larson $\mathrm{T}$, Hadsall $\mathrm{R}$, Uden $\mathrm{D}$, Blade $\mathrm{M}$, Branstad R. Integrating a pharmacist into a home healthcare agency care model. Home Healthc Nurse. 2014;32(3):146-152.

37. Kogut S, Goldstein E, Charbonneau C, Jackson A, Patry G. Improving medication management after a hospitalization with pharmacist home visits and electronic personal health records: an observational study. Drug Healthc Patient Saf. 2014;6:1-6.

38. Hanna M, Larmour I, Wilson S, O'Leary K. The impact of a hospital outreach medication review service on hospital readmission and emergency department attendances. J Pharm Pract Res. 2016; 46(2):112-121.

39. Hamano J, Ozone S, Tokuda Y. A comparison of estimated drug costs of potentially inappropriate medications between older patients receiving nurse home visit services and patients receiving pharmacist home visit services: a cross-sectional and propensity score analysis. BMC Health Serv Res. 2015;15(1):73.

40. Reidt $\mathrm{S}$, Holtan $\mathrm{H}$, Larson $\mathrm{T}$, et al. Interprofessional collaboration to improve discharge from skilled nursing facility to home: preliminary data on postdischarge hospitalizations and emergency department visits. J Am Geriatr Soc. 2016;64(9):1895-1899.

41. Shcherbakova N, Tereso G. Clinical pharmacist home visits and 30-day readmissions in Medicare Advantage beneficiaries. J Eval Clin Pract. 2015;22(3):363-368.

42. Cheen M, Goon C, Ong W, et al. Evaluation of a care transition program with pharmacist-provided home-based medication review for elderly Singaporeans at high risk of readmissions. Int J Qual Health Care. 2016;29(2):200-205.

43. Moultry A, Poon I. Perceived value of a home-based medication therapy management program for the elderly. Consult Pharm. 2008;23(11): 877-885.

44. MacAulay S, Saulnier L, Gould O. Provision of clinical pharmacy services in the home to patients recently discharged from hospital: a pilot project. Can J Hosp Pharm. 2008;61(2):103-113.

45. Stell R, Bonollo M, Fiddes K, Dooley M. Successful integration of a clinical pharmacist into a disease management unit. $J$ Pharm Pract Res. 2008;38(2):132-136.

46. Flanagan P, Pawluk S, Bains S. Opportunities for medication-related support after discharge from hospital. Can Pharm J. 2010;143(4):170-175.

47. Eichenberger P, Haschke M, Lampert M, Hersberger K. Drug-related problems in diabetes and transplant patients: an observational study with home visits. Int J Clin Pharm. 2011;33(5):815-823.

48. Hussainy S, Box M, Scholes S. Piloting the role of a pharmacist in a community palliative care multidisciplinary team: an Australian experience. BMC Palliat Care. 2011;10(1):16.

49. Castelino R, Bajorek B, Chen T. Are interventions recommended by pharmacists during Home Medicines Review evidence-based?. J Eval Clin Pract. 2010;17(1):104-110.

50. Willis J, Hoy R, Jenkins W. In-home medication reviews: a novel approach to improving patient care through coordination of care. J Community Health. 2011;36(6):1027-1031.

51. White L, Klinner C. Medicine use of elderly Chinese and Vietnamese immigrants and attitudes to home medicines review. Aust J Prim Health. 2012;18(1):50-55.

52. Novak C, Hastanan S, Moradi M, Terry D. Reducing unnecessary hospital readmissions: the pharmacist's role in care transitions. Consult Pharm. 2012;27(3):174-179.

53. Kwint H, Faber A, Gussekloo J, Bouvy M. The contribution of patient interviews to the identification of drug-related problems in home medication review. J Clin Pharm Ther. 2012;37(6):674-680.

54. Flanagan P, Kainth S, Nissen L. Satisfaction survey for a medication management program: satisfaction guaranteed?. Can J Hosp Pharm. 2013;66(6):355-360.

55. Martins B, Aquino A, Provin M, Lima D, Dewulf N, Amaral R. Pharmaceutical care for hypertensive patients provided within the family health strategy in Goiânia, Goiás, Brazil. Braz J Pharm. 2013;49(3):609-618.

56. Moultry A, Pounds K, Poon I. Managing medication adherence in elderly hypertensive patients through pharmacist home visits. Consult Pharm. 2015;30(12):710-719.
57. Poon L, Wang L, Moody S, Proffitt L. Evaluation of pharmacy resident and student recommendations made before and after home-based primary care patient visits. Consult Pharm. 2015;30(1):45-49.

58. Onda M, Imai H, Takada Y, Fujii S, Shono T, Nanaumi Y. Identification and prevalence of adverse drug events caused by potentially inappropriate medication in homebound elderly patients: a retrospective study using a nationwide survey in Japan. BMJ Open. 2015;5(8):e007581.

59. Kalista T, Lemay V, Cohen L. Postdischarge community pharmacist-provided home services for patients after hospitalization for heart failure. J Am Pharm Assoc. 2015;55(4):438-442.

60. Hanna M, Larmour I, Wilson S, O'Leary K. Patient and general practitioner perspectives of the Hospital Outreach Medication Review service at Monash Health. J Pharm Pract Res. 2015;45(3):282-290.

61. Ahn J, Park JE, Anthony C, Burke M. Understanding, benefits and difficulties of home medicines review - patients' perspectives. Aust Fam Physician. 2015;44(4):249-53.

62. Reidt S, Sibicky, S, Yarabinec A. Transitional care units: expanding the role of pharmacists providing patient care. Consult Pharm. 2016:31(1): 44-49.

63. Bailey J, Surbhi S, Bell P, Jones A, Rashed S, Ugwueke M. SafeMed: Using pharmacy technicians in a novel role as community health workers to improve transitions of care. J Am Pharm Assoc. 2016;56(1):73-81.

64. Surbhi S, Munshi K, Bell P, Bailey J. Drug therapy problems and medication discrepancies during care transitions in super-utilizers. J Am Pharm Assoc. 2016;56(6):633-642.e1.

65. Walus AN, Woloschuk DMM. Impact of pharmacists in a communitybased home care service: a pilot program. Can J Hosp Pharm. 2017;70(6): 435-442.

66. Costa D, Van C, Abbott P, Krass I. Investigating general practitioner engagement with pharmacists in Home Medicines Review. J Interprof Care. 2015;29(5):469-475.

67. Houle S, MacKeigan L. Home care pharmacy practice in Canada: a cross-sectional survey of services provided, remuneration, barriers, and facilitators. Can J Hosp Pharm. 2017;70(4):294-300.

68. Bhattacharya D, Wright $\mathrm{D}$, Purvis J. Pharmacist domiciliary visiting in England: identifying the characteristics associated with continuation. Pharm World Sci. 2007;30(1):9-16.

69. Chancheochai S, Sakulbumrungsil R, Ngorsurachet S. Preference on medication therapy management (MTM) service: results from discrete choice experiment. Thai J Pharm Sci. 2015;39(3):119-126.

70. Ensing H, Koster E, Sontoredjo T, van Dooren A, Bouvy M. Pharmacists' barriers and facilitators on implementing a post-discharge home visit. Res Social Adm Pharm. 2016;13(4):811-819.

71. Bell J, Aslani P, McLachlan A, Whitehead P, Chen T. Mental health case conferences in primary care: content and treatment decision making. Res Social Adm Pharm. 2007;3(1):86-103.

72. Traynor K. Midwest healthcare group puts pharmacists in patients homes. Am J Health Syst Pharm. 2016;73(7):428-429.

73. Stafford L, Peterson G, Bereznicki L, Jackson S, Tienen E. Training Australian pharmacists for participation in a collaborative, homebased post-discharge warfarin management service. Pharm World Sci. 2010;32(5):637-642.

74. Crockett B, Jasiak K, Walroth T, Degenkolb K, Stevens A, Jung C. Pharmacist involvement in a community paramedicine team. $J$ Pharm Pract. 2016;30(2):223-228.

75. Bailey A, Moe G, Moe J, Oland R. Implementation and evaluation of a community-based medication reconciliation (CMR) system at the hospital-community interface of care. Healthc Q. 2009;13(sp):91-97.

76. Pherson E, Shermock K, Efird L, et al. Development and implementation of a postdischarge home-based medication management service. Am J Health Syst Pharm. 2014;71(18):1576-1583.

77. Toh C, Jackson B, Gascard D, Manning A, Tuck E. Barriers to medication adherence in chronic heart failure patients during home visits. $J$ Pharm Pract Res. 2010;40(1):27-30.

78. Monte S, Passafiume S, Kufel W, et al. Pharmacist home visits: a 1-year experience from a community pharmacy. $\mathrm{J}$ Am Pharm Assoc. 2016;56(1):67-72. 
79. Sheridan J, Butler R, Brandt T, Harrison J, Jensen M, Shaw J. Patients' and pharmacists' perceptions of a pilot Medicines Use Review service in Auckland, New Zealand. J Pharm Health Serv Res. 2011;3(1):35-40.

80. White L, Klinner C, Carter S. Consumer perspectives of the Australian Home Medicines Review Program: benefits and barriers. Res Social Adm Pharm. 2012;8(1):4-16.

81. Rojas-Fernandez C, Patel T, Lee L. An interdisciplinary memory clinic. Ann Pharmacother. 2014;48(6):785-795

82. Traynor K. Virginia pharmacist makes house calls. Am J Health Syst Pharm. 2015;72(13):1078-1079..

83. Elliott L, Henderson J, Neradilek M, Moyer N, Ashcraft K, Thirumaran R. Clinical impact of pharmacogenetic profiling with a clinical decision support tool in polypharmacy home health patients: a prospective pilot randomized controlled trial. PLOS ONE. 2017;12(2):e0170905.

84. Riker G. Pharmacists can bridge the education gap - at home and in community - generations. J Amer Soc on Aging. 2011;35:75-77.
85. Jennings E. A Pharmacist Who Makes Home visits. Generations J of American Society on Aging. 2011;35:72-74.

86. Papastergiou J, Zervas J, Li W, Rajan A. Home medication reviews by community pharmacists. Can Pharm J. 2013;146(3):139-142.

87. Traynor K. Pharmacists' home visits target adherence in behavioral health patients. Am J Health Sys Pharm. 2017;74(16):1210-1211.

88. Matthies G. Practice spotlight: emergency department pharmacist who makes house calls. Can J Hosp Pharm. 2012;65(2):147.

89. Blain L, Flanagan P. Exploring the practical application of the concept of frailty in pharmacy practice. Can Pharm J. 2018;151(1): 13-16.

90. Kwint H-F, Bermingham L, Faber A, Gussekloo J, Bouvy ML. The relationship between the extent of collaboration of general practitioners and pharmacists and the implementation of recommendations arising from medication review. Drugs Aging. 2013;30(2):91-102.
Integrated Pharmacy Research and Practice

\section{Publish your work in this journal}

Integrated Pharmacy Research and Practice is an international, peer-reviewed, open access, online journal, publishing original research, reports, reviews and commentaries on all areas of academic and professional pharmacy practice. This journal aims to represent the academic output of pharmacists and pharmacy practice with particular focus on integrated care. All papers are carefully

\section{Dovepress}

peer reviewed to ensure the highest standards as well as ensuring that we are informing and stimulating pharmaceutical professionals. The manuscript management system is completely online and includes a very quick and fair peer-review system, which is all easy to use. Visit http://www.dovepress.com/ testimonials.php to read real quotes from published authors.

Submit your manuscript here: http://www.dovepress.com/integrated-pharmacy-research-and-practice-journal 